$\mathrm{Y}, \mathrm{AK} 347.243$

ББК 67.407 .1

DOI 10.22394/1682-2358-2017-6-67-74

O.A. Lyapina, Candidate of Sciences (Law), Docent of the Civil Law and Proceedings Department, Povolzhsky Institute of Management named after P.A. Stolypin, Branch of the Russian Presidential Academy of National Economy and Public Administration

M.V. Tverdova, post-graduate student of the Administrative and Criminal Law Department, Povolzbsky Institute of Management named after P.A. Stolypin, Branch of the Russian Presidential Academy of National Economy and Public Administration

\section{SEIZURE OF LAND FOR SUBSOIL USE: LEGAL REGULATION AND PRACTICE OF USE}

Legal aspects of seizing a land plot for subsoil use are considered. The quality of legal regulation and ways of solving land issues related to subsoil use, both in Russia and in some foreign countries, are analyzed.

Key words and combinations: land legislation, the right to a land plot, subsoil use right, seizure of land, category of land.
О.А. Мяпина, кандидат юридиеских наук, дочент кафедрьг гражданского праља и проиесса Поволжского института управления имени П.А. Стольпина - филиала Российской академии народного хозяйства и государственной службь при Президенте РФ (email: otdlaw@piuis.ru).

М.В. Твердова, аспирант кафедри административного и уголовного прања Поволжского института управления имени П.А. Стольтина - филиала Российской академии народного хозяйства и государственной службь при Президенте РФ (етаil: grebenshikovam@mail.ru).

\section{ИЗЬЯТИЕ}

\section{ЗЕМЕАЬНЫХ УЧАСТКОВ} $\triangle \Lambda Я$ ЦЕ $\Lambda Е И ̆$

\section{НЕАРОПОАЬЗОВАНИЯ:} ПРАВОВОЕ РЕГУАИРОВАНИЕ И ПРАКТИКА ПРИМЕНЕНИЯ

Аннотация. Рассматриваются правовые аспекты изъятия земельного участка для целей недропользования. Анализируется качество правового регулирования и способы решения на практике земельных вопросов, связанных с недропользованием, как в России, так и в некоторых зарубежных странах.

Ключевые слова и словосочетания: земельное законодательство, право на земельный участок, право недропользования, изъятие земельного участка, категория земельного участка.

B

подавляющем большинстве стран исторически соотношение прав на недра и на земельный участок играло большую роль. По мнению А. Штофа и ряда Аругих специацистов в области горного права $[1$, с. 2], 
метод решения этого вопроса определял характер всего горного законодательства конкретного государства. Практически во всем мире к моменту начаца массового освоения месторождений земельные участки, поА которыми расположены полезные ископаемые, уже имели собственников. Во многих государствах, в том числе в Англии и США, землевладелещ обладал безусловным правом на недра вплоть до начала ХХ в. В этом случае горнопромышленнику приходи-

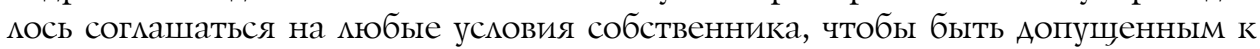
производству.

Как известно, границы месторождения далеко не всегда вписываются в граниџы одного земельного участка. Ситуаџия осложнялась еще и тем, что горнопромышиеннику приходицось иметь Аело с множеством собственников, каждый из которых устанавливац свои требования. Сумев получить доступ к земельному участку, он не имел гарантий, что ему будет разрешено пользоваться необходимыми дия горного дела поверхностными водами, Аорогами Амя перевозки к местам сбыта и т.А. При этом срок, на который земля преАоставцялась в аренду, мог быть настолыко мац, что горнопромышиенник успевац отработать мишь малую часть месторождения. Это приводицо к тому, что не-

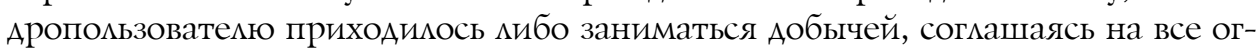
раничения, установленные договором аренды, мибо пытаться вести разработку трудноизвлекаемых природных ресурсов в сложных горно-геологических усмовиях на еще никем не занятых землях. Как отмечал Ажастис ФицА, один из наиболее известных юристов, занимавшихся толкованием ранних горных законов США, «изыскатель во многих случаях был оттеснен опередившим его фермером или скотоводом к самым высоким и крутым склонам или в чащу заповедного кеса» [2, с. 14].

В США первой реальной попыткой утверждения на законодательном уровне механизмов передачи земли недропользователю явицось принятие Актов Конгресса 1866 и 1870 г. В континентальной Европе правовая защита недропользователя появилась несколько ранее. Так, австрийский и прусский горные законы подробно описывали, что имел право делать горнопромышленник на предоставленном ему земельном участке, а собственник был обязан допустить его к производству. По мере повышения значимости горной промышиенности Аля экономики разных стран повсеместно уделялось все большее внимание вопросам предоставления земельных участков горнопромышиенникам. Законодатели стали предпринимать попытки дать недропользователю возможность получить землю на адекватных условиях.

На современном этапе подавцяющее большинство стран регулируют в той или иной форме предоставление земли дия нужА неАропользователя. Чаще всего этот вопрос хорошо освещен и существует подробно описанная процедура. Несмотря на это, вопросы доступа к земельному участку по-прежкнему рассматриваются недропользоватемями в мировой практике как один из кАючевых правовых рисков при реализации горнопромышиенного проекта. Законы, касающиеся предоставления недропользователю земельных участков, значительно отличаются не только в разных странах, но и зачастую в разных областях / штатах / регионах одной страны. Такая разница сильно заметна в 
Канаде и США, где каждый штат имеет свои законы, регулирующие земельные вопросы.

В ряде стран риск неполучения доступа к земельному участку может быть Аовольно серьезным, особенно если речь идет об иностранном инвесторе. Именно поэтому в Обзоре рисков в горной отрасли, опубцикованном Австралийским университетом горного дела и метамлургии, отказ в предоставмении земли рассматривается как главный риск нетехнического характера [3, с. 607].

В худшем случае получить право пользования земельным участком не получится и, соответственно, не удастся реализовать проект, в связи с чем инвесторы не смогут компенсировать уже произведенные затраты. Чаще всего при соблюдении ряда условий получить доступ к земельному участку возможно, но значительные временные потери могут привести и к дополнительным затратам. Риск неполучения доступа к земельному участку - одна из существенных причин, по которой инвесторы опасаются направцять ресурсы в горнопромышиенные проекты на территории многих стран Африканского континента и некоторых стран Азии. Во многих штатах Америки долгий процесс получения земли также явмяется фактором, снижающим инвестиционную привлекательность сферы недропользования.

В џелом, несмотря на множество отличий в национальном регулировании предоставления земли для целей неАропользования, все страны можно разделить на Аве условные группы в зависимости от Аействующего соотношения прав на недра и на земельный участок. Во все большем количестве стран, в том числе и в России, на данном этапе установлена государственная собственность на недра. Этот режим предполагает изъятие участка Аля государственных нужА в случае необходимости ведения на нем разведКи и добычи полезных ископаемых.

Тем не менее по-прежнему имеются страны, где неАра принадлежат собственнику земельного участка. При этом во второй группе государств четко прослеживается тенденџия планомерного ограничения собственника земли в его правах. Уменьшается глубина залегания помезных ископаемых, на которую распространяется собственность. Вводится также обязанность заключить договор аренды с недропользователем на детально прописанных типовых условиях. В реальной практике для самого собственника может оказаться более удобным вариант выкупа его участка, так как использовать его по назначению посме проведения горных работ часто уже не преАставмяется возможным.

Правовое регулирование изъятия земельного участка дмя целей неАропользования в России преАставмяет собой приоритетное направмение правотворческой деятельности в целях обеспечения устойчивого развития и экологической безопасности. В апреле 2015 г. вступили в силу нормы Земельного кодекса Российской Федерации, сушественным образом изменившие порядок получения земли дия цемей недропользования.

В ЗК РФ была добавлена отдельная глава, посвяшенная вопросам изъятия земельного участка. К числу важных для неАропользователей норм можно 
отнести следующее: во-первых, появление возможности проведения процедуры изъятия участка не только по иниџиативе органов исполнительной вцасти, но и по ходатайству самого неАропользователя; во-вторых, установмение четких сроков, отведенных на выполнение основных этапов процесса изъятия.

Аля недропользователя эти изменения, несомненно, носят прогрессивный характер, так как они уменьшают его зависимость от действий органов исполнительной власти, не заинтересованных в быстром решении земельного вопроса, а иногда и затягивающих по разным причинам процесс изъятия земельного участка. С принятием соответствующих поправок в Земельном кодесе РФ органы исполнительной власти и местного самоуправления обязаны:

- в течение пяти рабочих Аней возвратить ходатайство без рассмотрения в случае, если ходатайство по форме и содержанию не соответствует установменным требованиям;

- в течение 30 дней с момента получения ходатайства направить запрос в орган регистрации прав на недвижимое имущество в целях выявления правообладателей земемьных участков;

- в случае отсутствия сведений о правообладателях в ЕАином государственном реестре недвижимости (ЕГРН) в течение 10 Аней с момента получения ответа из органа Росреестра запросить сведения об имеющихся правообладателях в архивах, органах государственной власти, органах местного самоуправления (послеАние, в свою очередь, обязаны предоставить ответ на запрос в течение пяти Аней);

- опубликовать сообщение о планируемом изъятии и разместить его на информационном щите в границах населенного пункта, на территории которого расположены участки;

- после принятия решения об изъятии в течение 10 Аней опубликовать его и направить копию недропользователю.

Аля правообладателя земельного участка также установлены сроки:

- 60 Аней с момента опубликования сообщения об изъятии на подачу заявления об учете его прав;

- 90 Аней на подписание соглашения об изъятии мибо на направление предложения об изменении условий соглашения.

Недостатком рассматриваемой процедуры, установменной Земельным коАеком РФ, явцяется отсутствие максимацьных сроков Аля некоторых этапов изъятия. Общий срок изъятия по-прежнему может увеличиться в случае необходимости обращения в суд при отказе правообладатемя участка от подписания соглашения об изъятии. Тем не менее появление детального описания на законодательном уровне процедуры изъятия земельного участка, снижает риск змоупотреблений со всех сторон и существенного затягивания процесса.

Схематически процедура изъятия участка Амя целей неАропользования представлена на рисунке.

70 Bulletin of the Volga Region Institute of Administration • 2017. Vol. 17. № 6 


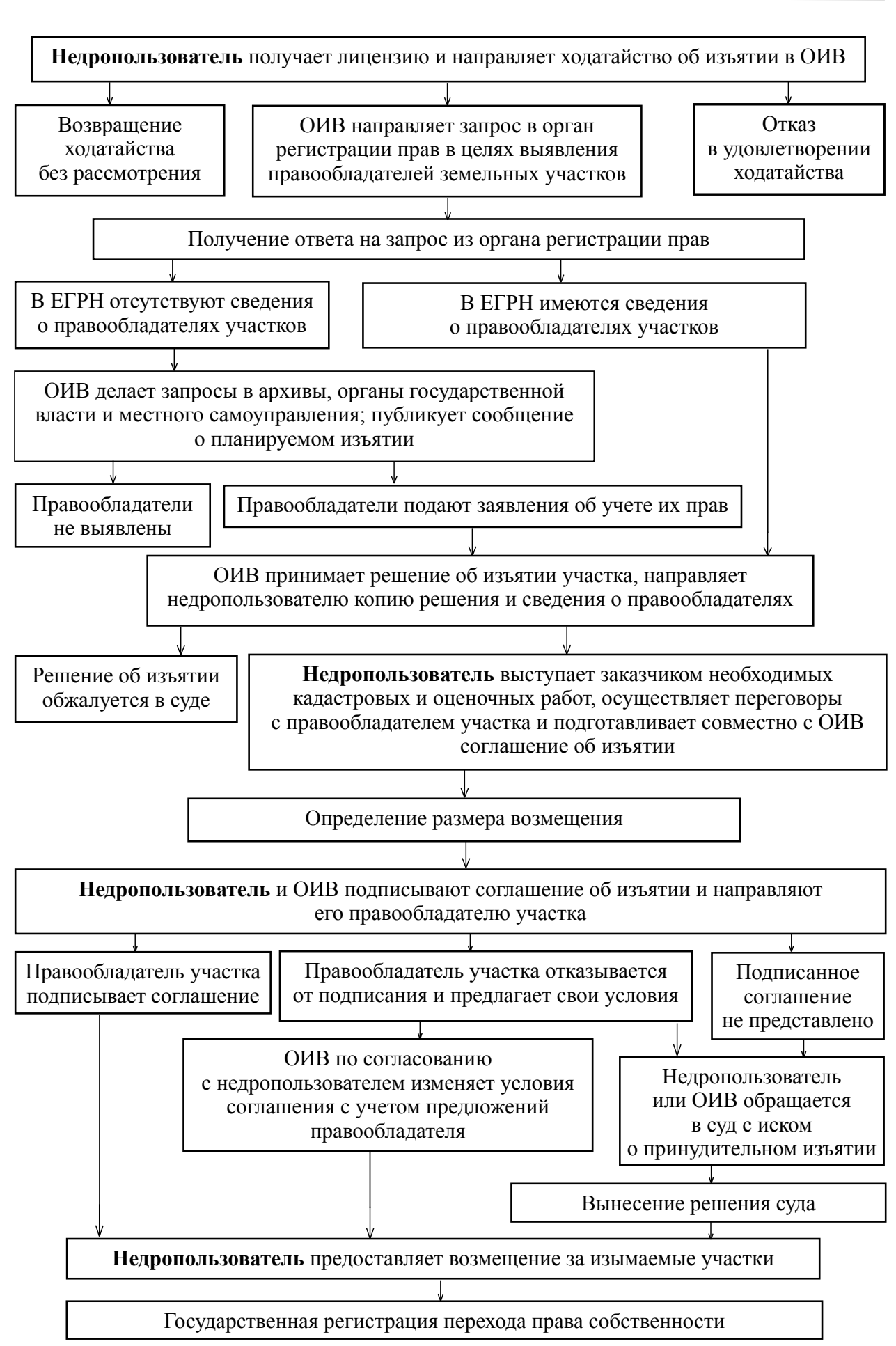

Вестник Повоцжского института управцения

- 2017. Том 17. № 6 
Наиболее проблемный вопрос, связанный с изъятием земельных участков, определение размера возмешения правообладателю. По сути, сокрашение сроков изъятия участка не явмяется негативным фактором дмя правообладателя, не заинтересованного долго находиться в состоянии неопределенности. Аیя него намного важнее получить достойную компенсацию за изымаемый участок, расположенные на нем объекты недвижимости и возможные убытки. С Аругой стороны, несмотря на большую освешенность вопроса нарушения прав собственника участка, известны случаи предоставления неадекватно минимальных компенсаций за изымаемый участок. Имеются и змоупотребления с Аругой стороны, когда собственник пытается завысить сумму понесенных убытков, полагая, что Аля горнодобывающей компании такие расходы не существенны. В действительности же для недропользователя, нередко приходится нужно заниматься изъятием десятков земельных участков, удовлетворение чрезмерно завышенных требований множества прежних правообладателей может привести к непредсказуемым и экономически необоснованным финансовым затратам.

Размер возмешения за участок и расположенные на нем объекты недвижимости опредемяется на основе оџенки их рыночной стоимости. Такой подход имеет, безусловно, положительное значение не только для правообладателя участка, но и для недропользователя. Это объясняется тем, что, несмотря на проведение государственной кадастровой оценки земельных участков, объектов недвижимости и установление их кадастровой стоимости с закреплением в ЕГРН, в ряде регионов России кадастровая стоимость значительно превышает рыночную. Такое обстоятельство влечет за собой восприятие указанного механизма как экономически необоснованного и несправедцивого и порожАает многочисленные судебные разбирательства по оспариванию кадастровой стоимости и определению рыночной стоимости соответствующего земельного участка [4-6].

Отметим также прогрессивность положения ст. 56.9 ЗК РФ, которая закАючается в установцении обязанности органов исполнительной власти не только уведомлять правообладатемя о планируемом изъятии, но и направцять ему отчет об оџенке рыночной стоимости изымаемых земельных участков и расположенных на них объектов недвижимого имущества [7]. Таким образом, у правообладателя появилась возможность узнать несколько ранее о размере положенного ему возмещения и успеть принять меры в случае явного несоответствия стоимости участка заявленной в оџенке сумме.

Наибольшие трудности возникают в связи с оџенкой понесенных правообладателем убытков, в том числе упущенной выгоды. Судебная практика по Аанному вопросу неоднозначна. Например, собственникам участков не всегда удается получить компенсацию за убытки, связанные с переездом и сменой места жительства. Сложность в определении упущенной выгоды состоит в том, что она носит вероятностный характер и почти всегда рассчитывается приблизительно. В соответствии с правовой позиџией, изложенной в п. 14 постановления Пиенума Верховного Суда РФ от 23 июня 2015 г. № 25 «О применении судами некоторых положений раздела I части первой Гражданского

72 Bulletin of the Volga Region Institute of Administration • 2017. Vol. 17. № 6 
кодекса Российской Федерации», сам по себе этот факт не может явцяться основанием для отказа в иске. Помимо этого, имеются случаи предоставления в качестве обоснования упущенной выгоды фиктивных договоров и совершение иных недобросовестных действий собственником участка. Именно поэтому необходимость изъятия участка, используемого Аля преАпринимательской деятельности, предполагает дополнительные риски для неАропользователя.

С учетом изможкенного, по нашему мнению, целесообразно разработать и утверАить Правительством РФ порядок расчета убытков при изъятии земельных участков для целей недропользования. Это сделает более понятным и прозрачным проџесс изъятия Аля обеих сторон и обеспечит его экономическую обоснованность и нормативно-правовую определенность.

Необходимо обратить внимание и на то обстоятельство, что на протяжении Алительного времени у недропользователей возникал ряд трудностей, связанных с изменением цемевого назначения участка. В частности, проблемы появлялись в случае, если земельный участок брался в аренду. Иногда уже посме получения доступа к земельному участку, выяснялось, что использовать его для цемей недропользования невозможно. Известны случаи проведения аукционов, где выставмяляя участок неАр, для разработки которого нужен земельный участок, не подмежкащий использованию для заявленных цемей. В качестве примера можно привести определение Высшего Арбитражного Суда РФ от 21 января 2009 г. № 17517/08, признавшего недействительным аукцион, где Аля осуществления добычи бым необходим участок, находящийся в границах зеленой зоны земель кесного фонда.

Важным положением, действующим с 2015 г., явмяется возможение на исполнительные органы государственной вмасти или органы местного самоуправления обязанности по переводу земель в нужную категорию в случае осуществления изъятия земельного участка для џемей недропользования. При этом в соответствии со ст. 6 Федерального закона «О переводе земель или земельных участков из одной категории в Аругую» сделать это указанные органы Аолжны Ао предоставления недропользователю изъятого земельного участка [8] .

Несмотря на то что адекватное развитие земельного законодательства в этом направлении обеспечимо решение части вопросов, возникающих в судебной практике, Аля недропользователя по-прежкнему остается важным еще на этапе оценки целесообразности инвестирования проверить виА разрешенного использования испрашиваемых земельных участков. Следует учитывать, что перевод земель из состава особо охраняемых территорий и объектов в Аругую категорию невозможен. Перевод из категории земель сельскохозяйственного назначения выполним только при наличии утвержденного проекта рекультивации земель.

На землях месного фонда в искмючительных случаях допускается разработка месторождений полезных ископаемых. Но при этом нельзя применить процедуру изъятия, а также перевести земельный участок в другую категорию. Получить месной участок можно в аренду при соблюдении требований, установленных месным планом субъекта РФ и цесохозяйственным регламентом месничества. Кроме того, Порядок использования месов дяя выполнения 
работ по геологическому изучению недр, Аля разработки месторождений помезных ископаемых [9] устанавливает значительное число ограничений по использованию месных участков. Например, Аля размещения объектов горноАобывающего производства должны использоваться в первую очередь участки невозобновившихся вырубок, гарей, пустырей, места, гАе произрастают низкополнотные месные насаждения.

Резюмируя, можно утверждать, что в настоящий момент вопрос предоставмения земельных участков Аля целей недропользования в значительной степени урегулирован, чему способствовало развитие земельного законодательства в анализируемой сфере. Проџедура изъятия участка в общих чертах сходна как Аля целей недропользования, так и Аля иных государственных или муниципальных нужа. ОАнако отметим, что судебная практика по делам, связанным с изъятием участков дия целей пользования недрами, успела сформироваться в меньшей степени, чем по изъятию Аля Аругих целей. В основном судебные споры вызваны несоблюдением установленной ЗК РФ процеАуры изъятия, в том числе в части сроков информирования о планируемом изъятии и иных процессуальных моментов. Анализ судебной практики позволяет сделать вывод о том, что даже незначительное отступление от установленной процеАуры может повлечь за собой отказ в иске органа исполнительной власти (местного самоуправления) или недропользователя о принудительном изъятии земельного участка Аля столь стратегически значимой цели - недропользования.

\section{Библиографический список}

1. Штоф А. Горное право: сравнительное изложение горных законов. СПб., 1896.

2. MacFarren H.W. Mining law for the prospector, miner, and engineer. Mining and Scientific Press, San Francisco, and the Mining Magazine; London, 1911.

3. Mineral Resource and Ore Reserve Estimation. The AusIMM Guide to Good Practice. 2017. URL: https://sharpbook.net/books/mineral-resource-and-ore-reserve-estimation-the-ausimm-guideto-good-practice

4. О некоторых вопросах, возникающих при рассмотрении судами дел об оспаривании результатов определения кадастровой стоимости объектов недвижимости: постановление Пленума Верховного Суда Российской Федерации от 30 июня 2015 г. № 28. URL: http://www. consultant.ru/document/cons_doc_LAW_181899/

5. Определения Верховного Суда Российской Федерации от 4 февр. 2015 г. по делу № 25АПГ14-7; от 18 февр. 2015 г. № 53-АПГ14-15 и № 53-АПГ14-16; от 19 авг. 2015 г. № 32-АПГ15-3; от 26 авг. 2015 г. № 32-АПГ15-4 [Электронный ресурс]. Доступ из СПС «КонсультантПлюс».

6. Решения Саратовского областного суда от 7 апр. 2015 г. по делу № 3-1/2015; от 8 апр. 2015 г. по делу № 3-3/2015 [Электронный ресурс]. Доступ из СПС «КонсультантПлюс».

7. Земельный кодекс Российской Федерации от 25 окт. 2001 г. № 136-ФЗ (в ред. от 29 июля 2017 г.). URL: http://www.consultant.ru/document/cons_doc_LAW_33773

8. О переводе земель или земельных участков из одной категории в другую: Федер. закон от 21 дек. 2004 г. № 172-ФЗ (в ред. от 29 июля 2017 г.). URL: http://www.consultant.ru/document/ cons_doc_LAW_50874

9. Об утверждении Порядка использования лесов для выполнения работ по геологическому изучению недр, для разработки месторождений полезных ископаемых: приказ Рослесхоза от 27 дек. 2010 г. № 515 (в ред. от 26 июня 2012 г.). URL: http://www.consultant.ru/document/ cons_doc_LAW_113907

\footnotetext{
74 Bulletin of the Volga Region Institute of Administration • 2017. Vol. 17. № 6
} 